\title{
Life as a neurosurgeon
}

\author{
Jacqui Wise
}

London, UK

Neurosurgeons assess, diagnose, and undertake surgery to treat disorders of the central nervous system, including the brain and spine.

The work is varied and challenging. Neurosurgeons deal with patients of all ages, from newborn babies to elderly people, and treat a range of conditions (see box 1).

Neurosurgeons increasingly work as part of a large multidisciplinary team. Within the operating theatre they work with other surgeons, anaesthetists, trainee doctors, theatre nurses, and medical students. Outside of theatre they work closely with radiologists who use a range of diagnostic tools, including computed tomography and magnetic resonance imaging scans and other techniques such as brain angiography. They also work with other physicians and surgeons, including neurologists, oncologists, ophthalmologists, and paediatricians.

\section{A typical day}

The working day is usually long. It starts around 730 am to 8 am with a ward round and a check on any patients in the intensive treatment unit (ITU). Each morning a review meeting is held to discuss patients referred in the preceding 24 hours and to review all the imaging.

If the neurosurgeon has a theatre list that day they would go to theatre, do pre-checks, meet with the other theatre staff, and discuss each patient on the list. Surgery would start around 9 to 930 am with a series of cases until around $6 \mathrm{pm}$

Some procedures may be straightforward and quick-putting in an intracranial pressure monitor takes around 30 minutes, for example, while a shunt revision for hydrocephalus takes around an hour. Other operations can be long and complex-it can take 10 to 11 hours to deal with a major tumour underneath the brain and if an operation involves other specialists such as plastic surgeons it can take up to 15 hours.

In between cases neurologists usually go back to the office to deal with paperwork such as signing letters, looking at results, and answering queries from patients and GPs. At the end of the surgical list they check on patients and speak to their loved ones, usually leaving the hospital between $7 \mathrm{pm}$ and $8 \mathrm{pm}$

Non-theatre days are more likely to end around $6 \mathrm{pm}$ These days could involve outpatient clinic sessions, which may mean assessing new and follow-up patients and helping patients come to terms with life after treatment.

There would still be the usual ward rounds, visits to patients on the ITU, and paperwork. There may also be multidisciplinary team meetings where patients who are referred to the service are discussed, as well as weekly morbidity and mortality meetings attended by all members of staff.

Emergency and unscheduled referrals from hospitals within the regional catchment area account for a large proportion of the neurosurgical caseload. Out-of-hours activity is commonplace. Consultants would usually be on call on a one in eight or one in nine rota. Junior doctors would also do similar on-call duties in line with the European Working Time Directive limits.

Junior doctors attend the morning review meeting and do ward rounds to formally review each patient every day. If they are attached to a surgeon who is in theatre they would attend, assist, watch, and learn, gradually carrying out procedures as they become more experienced. They would also carry out the outpatient sessions and attend formal structured training sessions.

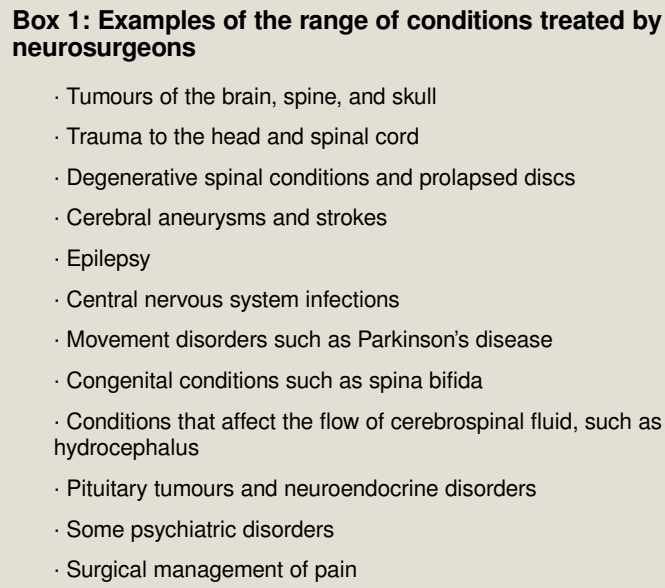

Box 2: Best things about the job

- The nature of the work means you develop close relationships with patients and their families

- It is rewarding, offering the ability to vastly improve a patient's quality of life

- The level of diversity-you will treat patients of all ages with a variety of disease processes, including trauma

- Neurosurgery is at the forefront of medical and surgical advances - Run-through training means no additional competitive step when a programme has been entered 


\section{Box 3: Worst things about the job}

- There are no down days

- The days and nights can be very long

- You may have to break bad news to patients and their families

- The environment can be stressful with not much margin for error

- Units can be far apart and tend to be in large cities so not suitable if you want a more rural environment

- High on-call duties

\section{Box 4: Skills needed}

Stamina to cope with long hours and demanding nature of the work . Compassion and emotional strength in order to manage very sick patients Ability to listen and speak to patients and their families

Technical skills and a high degree of manual dexterity, good hand-eye coordination, excellent vision, and visual-spacial awareness

Digitally aware as the job will increasingly involve more digital support The ability to lead and manage a team effectively

Good organisational skills

A strong interest in anatomy and physiology

\section{Useful organisations}

The Society of British Neurological Surgeons provides lots of useful information on training and continued professional development ${ }^{1}$

The British Neurosurgical Trainees Association ${ }^{2}$ represents the opinions of trainees in neurosurgery. Their meetings offer an opportunity to meet other trainees and to provide a forum for discussion of issues relevant to training

The Royal College of Surgeons offers a confidential support and advice service to support surgeons in difficulty. ${ }^{3}$ It also runs a surgeon to surgeon helpline: 02078696221

Wellbeing support is available through the BMA. ${ }^{4}$ Confidential 24/7 counselling and peer support services are open to all doctors and medical students on 0330123 1245. www.bma.org.uk/advice/work-life-support/ your-wellbeing/counselling-and-peer-support

Doctors.net ${ }^{5}$ and Support4Doctors ${ }^{6}$ provide a range of information and support including financial advice and clinical concerns

The Neurology and Neurosurgery Student Interest Group is a UK based organisation for medical students and junior doctors. ${ }^{7}$ It provides up-to-date careers and admissions information as well as evaluating the latest research in the field of neuroscience

Women in Surgery is a national initiative dedicated to support female surgeons $^{8}$

Society of British Neurological Surgeons. www.sbns.org.uk.

British Neurosurgical Trainees' Association. http://e1v1m1.co.uk.

3 Royal College of Surgeons of England. Confidential support and advice service for surgeons. www.rcseng.ac.uk/careers-in-surgery/csas.

4 BMA. Wellbeing support services. www.bma.org.uk/advice/work-life-support/your-wellbeing/ counselling-and-peer-support

5 Doctors.net.uk. www.doctors.net.uk.

Royal Medical Benevolent Fund. www.support4doctors.org.

Neurology and Neurosurgery Interest Group. www.nansig.org

Royal College of Surgeons of England. Women in surgery. www.rcseng.ac.uk/careersin-surgery/women-in-surgery.

Published by the BMJ Publishing Group Limited. For permission to use (where not already granted under a licence) please go to http://group.bmj.com/group/rights-licensing/ permissions 